\title{
Aspectos sociopolíticos da epidemia de toxoplasmose em Santa I sabel do Ivaí (PR)
}

\author{
Socio-political aspects of toxoplasmosis epidemic \\ in Santa Isabel do Ivaí, Paraná State, Brazil
}

\author{
Márcio J oséde Almeida ${ }^{1}$ \\ LuziaH elena Herrmann de Oliveira ${ }^{2}$ \\ Roberta LemosFreire ${ }^{3}$ \\ Italmar Teodorico Navarro ${ }^{3}$
}

${ }^{1}$ Departamento deSaúde

Coletiva, Centro de

Ciências da Saúde,

Universidade Estadual de

Londrina. Rua Robert Koch

60, Cervejaria. 86038-440

Londrina PR.

marcioalmeida.consultoria@

hotmail.com

${ }^{2}$ Universidade Estadual de

Londrina.

${ }^{3}$ Departamento de M edicina

Veterinária Preventiva,

Centro de Ciências

Agrárias, Universidade

Estadual deLondrina.
Abstract In 2002, due to a toxoplasmosis epidemic Santa I sabel do I vaí, Paraná State, was the focus of sanitary investigations. Four hundred and twenty six individuals had serology suggestive of acute T. gondii infection (IgM reactor), considered the largest outbreak of toxoplasmosis ever reported in the world. This research was meant to identify actions carried out by the sanitation and health services sector at that time, highlighting the political conflicts that took place during the process and identifying the measures taken by the sanitary authorities during and after the epidemic period. This is an interdisciplinary study aimed at understanding major problems of public health like this one. The investigation was based on the contents of documents press and institutional - and interviews. According to official data, the epidemic was caused by the contamination of one of the water reservoirs that supply the city. This research showed that political and social factors, as the party instability and the level of political dependence of local society, were largely responsible for theoccurrence of the epidemic and for the difficulties faced by the health agents during such crisis.

Key words Public policies and health, Epidemic of toxoplasmosis, Toxoplasma, Sanitation and epidemics
Resumo Em 2002, o município de Santa Isabel do I vaí (PR), em virtude de uma epidemia de toxoplasmose, tornou-se lócus privilegiado de investi gações sanitárias. As informações disponíveis indicam tratar-se da maior já registrada no mundo: 426 pessoas apresentaram sorologia sugestiva deinfecção aguda por T. gondii (I gM reator). Esta pesquisa foi realizada com o objetivo de identificar as ações desenvolvidas pelos serviços de saúde e de saneamento durante o período, observando os conflitos políticos ocorridos no processo e identificando as medidas tomadas pelas autoridades sanitárias durante e após a epidemia. Trata-se de um estudo interdisciplinar, que busca a compreensão mais aprofundada e abrangente dos problemas de saúde pública. A investigação foi baseada na análise de conteúdo de documentos - da imprensa e institucionais - e entrevistas. Segundo dados oficiais, a causa da epidemia foi a contaminação de um dos reservatórios de água que abastecem a cidade. A pesquisa mostrou quefatores de ordem política e social, como a instabilidade partidária e o nível de dependência política da socie dade local, contribuíram para a ocorrência do surto epara as dificuldades enfrentadas pel osagentes de saúde no decorrer da crise.

Palavras-chave Políticas públicas e saúde, Epidemia de toxoplasmose, Toxoplasma, Saneamento básico e epidemias 


\section{Introdução}

O objetivo deste artigo é analisar a epidemia de toxoplasmose ocorrida no município de Santa I sabel do Ivaí (PR), nos meses de dezembro de 2001 a janeiro de 2002, a partir de um enfoque interdisciplinar que englobe, sobretudo, os aspectos sociopolíticos do surto. Procura-se identificar esistematizar os principais fatos eacontecimentos ocorridos durante o desenvolvimento da epidemia, procurando contribuir para a revisão de diretrizes no campo das políticas de saúde e de saneamento.

Santa Isabel do Ivaí éum pequeno município (9.154 habitantes) localizado no N oroeste do Paraná, cuja economia encontra-se predominantemente relacionada à agropecuária, à extração da madeira eà indústria de transformação. Embora a cidadeapresenteum índice de desenvolvimento humano (IDH) considerado médio - 0,758 - , sociologicamente pode ser definida como uma cidade tradicional, devido à sua estrutura produtiva predominantemente agrária eà falta de autonomia financeira, quea torna dependentedo poder estadual ${ }^{2}$. Como a maior parte das pequenas cidades brasileiras, Santa I sabel necessita das verbas estaduais e da União para se manter, pois a arrecadação municipal é irrisóriaª .

Em termos políticos, contudo, encontra-se plenamente inserida nos mecanismos procedimentais da democracia brasileira. Tal como de termina a constituição, encontram-se organizados e em funcionamento na cidade os conselhos de educação, de saúde, de assistência, e o dos direitos da criança e do adolescente ${ }^{4}$. A organização dos consel hos nas áreas de educação e saúde foi proposta pela Constituição Federal de 1988, com o objetivo de desconcentrar o poder administrativo e favorecer a participação da sociedade nos mecanismos decisórios em questões de seu interesse direto. Em termos de saneamento básico, o município é um dos poucos que não estadualizaram seus sistemas e conta atéhojecom Serviço Autônomo de Água e Esgoto (SAAE), o que, para os objetivos desta pesquisa, é um dado a ser salientado.

Também os partidos políticos encontram-se representados na política municipal. A sociedade democrática moderna é partidária, no sentido de quea competição político-institucional desenvolve-se através desse mecanismo e de que as organizações partidárias são canais que levam até as instâncias decisórias do Estado as demandas dos mais diversos grupos sociais. Competitividade partidária e alternância partidária de poder são indicadores de uma democracia em atividades. Entre 1996 e2002, onze partidos participaram das eleições no município de Santa Isabel ${ }^{6}$.

Além disso, o município éuma comarca, contando com juiz e promotor de Justiça. Estudos recentes sobre a atuação do Ministério Público brasileiro têm demonstrado a importância deste organismo para defender direitos dos segmentos sociaisnão organizados, daquel as pessoas que não conseguem, por meio dos canais políticos tradicionais (partidos, sindicatos e outros), fazer valer os seus direitos ${ }^{7,8}$.

De acordo com a proposta do movimento dascidades saudáveis, épossível desenvolver uma maior qualidade de vida no meio urbano, se forem incentivados processos de descentralização administrativa, participação comunitária e maior controle social sobre a política. A Constituição Federal de 1988, ao determinar a criação de conselhos municipais, estabelecer o pluripartidarismo, fortalecer os órgãos de Justiça e dotar os municípios de formas mais desconcentradas de poder, rumou nessa direção.

Observando-se, por essa ótica, a das formalidades jurídico-políticas, Santa I sabel do Ivaí encontra-se plenamente inserida na democracia. Entretanto, como se pretende demonstrar a seguir, nesse pequeno município, a regulamentação dos preceitos constitucionaistem sido insuficiente para garantir a plena participação política da sociedade e a qualidade de vida proposta pelo movimento das cidades saudáveis. A análise re trospectiva da epidemia de toxoplasmose é um exemplo do quanto tem sido difícil, em pequenos etradicionais municípios do interior, garantir direitos humanos elementares, como a qualidade da água consumida ou 0 atendimento à saúde.

\section{M ateriais emétodos}

A pesquisaédenatureza interdisciplinar efoi realizada durante os anos de 2003 a 2006. Seu arcabouço teórico-conceitual foi construído com base nos referenciais da atenção primária ambiental e da estratégia das cidades saudáveis. Atualmente, o Estado não é capaz de satisfazer a todas as de mandas da comunidade porque as estratégias nacionais demelhoria ambiental não contemplam suficientemente o âmbito local como um espaço prioritário de intervenção. A tendência éresolver os problemas ambientais a partir de uma perspectiva macro, sem desenvolver suficientemente as soluções locais. Institucionalmente, há uma debilidade na gestão ambiental dos municípios. 
O modelo de promoção do desenvolvimento autossustentado desenvolvido por Wright ${ }^{9}$ preconiza uma estratégia de ação interdisciplinar e busca a colaboração e a parceria de diferentes agentes e setores para elaborar, analisar e executar os planos, programas ou projetos. Se o marco conceitual propicia a participação junto com a ação, isso libera e outorga poder de decisão aos indivíduos, à comunidade eà sociedade. Criamse, assim, novos líderes para o desenvolvimento sustentado.

0 enfoque requer associar a relação dialética dosníveismacropolítico emicropolítico dequalquer situação para que a ação que se produza seja consequência da inter-relação entreesses dois níveis. 0 aspecto crítico desse modelo consiste em considerar a correlação entre as condições, a situação eos resultados ao analisar qual quer tema ou problema. A perspectiva holística tem em conta a interação multidimensional, a integração eo equilíbrio das relações entre o ser humano, 0 ambiente e a sociedade.

0 marco teórico fundamental do enfoque da atenção primária ambienta ${ }^{10}$ incorpora os conceitos de poder, conhecimento e liderança como fatores importantes para a tomada de decisões e a formulação de políticas em todos os níveis. Os princípios de interação, integração e equilíbrio são cruciais para poder negociar e compartilhar o poder, os conhecimentos e a liderança.

0 segundo componente conceitual da pesquisa, o movimento cidades saudáveis $s^{11}$, vem divulgando uma prática que representa uma nova forma de pensar e fazer saúde. 0 movimento tem como objetivo um produto social, a qualidade de vida da população e pressupõe a existência de problemas concretos de pessoas vivendo em um território. Representa, pois, uma nova forma de gestão municipal, baseada na intersetorialidade, na interdisciplinaridade ena participação social.

A análise de conteúdo e a reconstituição histórica da epidemia foram feitas com base na imprensa estadual (jornais Folha de Londrina, Jornal deLondrina eGazeta do Povo); em documentos oficiais (Secretaria de Saúde do Paraná, atas do Consel ho Municipal deSaúdeeda Câmara de Vereadores do município); em entrevistas semiestruturadas com lideranças políticas, comunitárias e agentes de saúde, totalizando dezesseis entrevistas; na bibliografia referente à questão .

Para participar das entrevistas, foram selecionadas, a partir de um estudo prévio, pessoas que sob perspectivas diferentes envolveram-se diretamente com a crise. 0 objetivo dessa seleção variada foi apresentar na pesquisa as diferentes visões do problema e assim obter uma descrição que respeite as normas da imparcialidade investigativa. Os dados da imprensa e os documentos oficiais serviram para dar embasamento factual à investigação. Optou-se por adotar a corrente metodológica que recomenda "a neutralização dos valores", obedecendo aos procedimentos indicados por Giovanni Sartori12: "(1) separar os juízos de fato dos juízos de valor; (2) verificar e descrever antes de atribuir valores; (3) ater-se a regras de imparcialidade, como apresentar com equidade todos os pontos de vista valorativos".

Como 0 artigo procura mostrar o impacto social provocado pela epidemia, foi considerado oportuno apresentar a fala dos entrevistados. Todas as entrevistas foram gravadas e as citações nominais foram formalmente permitidas por um termo de consentimento livre eesclarecido.

\section{Histórico da epidemia}

A toxoplasmose é uma zoonose de distribuição mundial, causada pelo protozoário T. gondii. Os felídeos são os hospedeiros definitivos e eliminam os oocistos do parasita nas fezes, contaminando o meio ambiente. 0 homem e os outros animais homeotérmicos são os hospedeiros intermediários. 0 homem adquire a infecção toxoplásmica principalmente pela ingestão de cistos teciduais em carne crua ou mal cozida deanimais infectados, pela ingestão de oocistos esporulados presentes no meio ambiente (água, solo, alimentos) ou de forma congênita, via transplacentária ${ }^{13,14}$.

A contaminação de reservatórios de água municipais com oocistos eliminados por felídeos infectados pode levar à ocorrência de surtos ou epidemias. Somente sistemas de tratamento de água completos e que prezam pela qualidade da água, desde a captação até a distribuição, são capazes de reter a maioria dos oocistos de T. gondii e de outros coccídeos nas etapas de coagulação, sedimentação efiltração. A desinfecção com cloro, normalmenterealizada nas estações detratamento de água, não inativa os oocistos de coccídeos e cistos de Giardia sp.

A descrição de surtos de toxoplasmose não é frequente e, na maioria dos casos, está associada a pequenos grupos. Os sinais clínicos geralmente são brandos ou inaparentes, devido à baixa patogenicidade da cepa e dose infectante ou à pronta resposta imunológica do hospedeiro, dificultando a notificação dos casos. 
Em 1995, ocorreu, no oeste do Canadá, uma epidemia de toxoplasmose envolvendo cem pessoas com idades entre seis e 86 anos. Tal epidemia foi relatada como a maior ocorrida no mundo, causada pela ingestão de água contaminada com oocistos de T. gondii ${ }^{15}$.

Em dezembro de 2001, tem início a epidemia de Santa Isabel do Ivaí. No período de novembro de 2001 a janeiro de 2002, aproximadamente seiscentos moradores procuraram os serviços de saúde apresentando sintomas compatíveis com a toxoplasmose aguda; 426 apresentaram sorologia sugestiva de infecção aguda por $\mathrm{T}$. gondii (IgM reator). Os principais sinais e sintomas foram cefaléia, febre, cansaço, mial gia, adenomegalia (cervical, axilar, inguinal) e perda de apetite. Sete casos ocorreram em gestantes, sendo que uma apresentou aborto espontâneo e seis tiveram filhos infectados, um deles com anomalia congênita grave, resultando em óbito. Em um primeiro exame oftalmológico, 176 casos foram avaliados, encontrando-se catorze (8\%) com alterações sugestivas da toxoplasmose ocular ${ }^{16}$.

0 surto ocorreu em virtude da contaminação de um reservatório de água da cidade que apresentava infiltrações por oocistos de fezes de gatos jovens que habitavam o local. Um dos fiIhotes capturados na casa das máquinas possuía sorologia positiva. A água era captada em poços artesianos e não passava por processos de coagulação ou filtração, sendo apenas clorada. Além dos indícios epidemiológicos, oocistos de T. gondii foram recuperados em uma caixa d'água de uma escola pública do município ${ }^{17}$. No estudo de caso-controle realizado, os fatores de risco associados à toxoplasmose na análise multivariada foram a utilização de água do reservatório habitado pelos gatos e presença de caixa d'água na residência ${ }^{18}$.

A distribuição geográfica dos casos demonstrou uma concentração na área central da parte baixa da cidade, região servida por um dos dois reservatórios municipais de água. A água que abastecia o reservatório era proveniente de um poço, do qual a água era bombeada, clorada e distribuída para o município. 0 tratamento da água não incluía o processo de coagulação, sedimentação e filtração; a cloração era inadequada. Aliás, mesmo que esta estivesse adequada, os oocistos permaneceriam "vivos".

Além disso, a área em que o reservatório estava localizado era aberta, permitindo o acesso de animais domésticos ou silvestres. H avia relatos que um gato doméstico vivia ehabitava dentro da casa de máquinas, em cima do reservató- rio. Um dos filhotes capturados apresentou sorologia positiva para toxoplasmose. 0 reservatório apresentava várias infiltrações e vazamentos, possibilitando a contaminação da água com oocistos. T. gondii foi detectado nas membranas utilizadas para filtrar a água da caixa d'água de uma escola municipal, que se encontrava fechada devido às férias escolares, por meio da inoculação em galinhas, suínos e também pela técnica da reação em cadeia pela polimerase (PCR).

\section{Narrativa da crise}

Os primeiros casos de toxoplasmose em Santa I sabel do I vaí foram confundidos com gripe e com dengue. 0 diagnóstico da toxoplasmose foi dado no início de dezembro, quando a esposa de um dos médicos do município, ex-secretário municipal de saúde e dono do hospital privado da cidade, foi infectada e os exames laboratoriais confirmaram a doença. A partir daí, a Secretaria Municipal de Saúdedo município resolveu realizar exames nas quarenta mulheres gestantes cadastradas no posto de saúde.

A Secretaria Municipal de Saúdeea 14a Regional de Saúde (RS) convocaram os funcionários e agentes comunitários para o plantão de véspera de $\mathrm{N}$ atal. A médica veterinária da 17a RS-Londrina, queé especializada no assunto, foi chamada para colaborar na organização dos trabal hos. Desde logo, ela alertou que o problema poderia vir da água. No município, o serviço de água é autárquico, com abastecimento por meio de poços artesianos. Um dos reservatórios ficava próximo ao matadouro e já apresentava problemas em sua estrutura. Coube a equipe de jornalistas da Folha de Londrina divulgar uma reportagem com a foto da gata com a seguinte legenda: "um gato éencontrado perto da casa ondeficam bombas d água que abastecem a cidade: protozoário tem no felino o hospedeiro natural" ${ }^{19}$. Contudo, autoridades ligadas ao Serviço Autônomo de Água e Esgoto do município insistiam em negar que o problema proviesse da água, lançando suspeitas sobre os alimentos, como a carne suína, 0 leite e as verduras. No início de janeiro, chegaram ao município sanitaristas da Secretaria Estadual de Saúde lotados em Curitiba. Esse grupo passou a cuidar do levantamento de dado ${ }^{20}$. I niciou-se, então, a busca pelos gatos do reservatório para os exames laboratoriais.

Em meados dejaneiro, o M inistério da Saúde enviou uma equipe do Centro Nacional de Epidemiologia (CENEPI) com o objetivo de realizar 
"estudo de caso controle" e ampliar as informações sobre o surto. Vieram também técnicos da Fundação Nacional de Saúde (FUNASA) e um representante da Secretaria Estadual de Saúde para elaborar um projeto de captação e distribuição da água. Era a esfera federal que passava aintervir.

Outro grupo presente nas ações em torno da crise sociossanitária que havia se instalado no município foi o dos pesquisadores da Universidade Federal do Rio Grande do Sul (UFRGS), responsáveis pelos exames oftalmológicos. Os oftalmologistas vieram por convite da Secretária Municipal deSaúde.

Em meados de janeiro, a epidemia de Santa I sabel do Ivaí já era considerada a "mais grave do mundo". Eram 135 casos confirmados, um caso de aborto e várias gestantes contaminadas. Os exames realizados pelos oftal mologistas constataram a existência de problemas oculares em 8\% dos 135 casos confirmados ${ }^{21}$. Segundo um dos pesquisadores da UFRGS, esse número tenderia a crescer nos próximos dois anos para algo em torno de $20 \%$ dos casos confirmados. H avia dificuldade em computar com rapidez um número tão alto de exames no posto de saúde. Na praça central da cidade, foi montado um posto avançado.

As entrevistas realizadas com os atores da crise mostram que o excesso de pessoas einstâncias atuando sem coordenação impediu que a crise fosse enfrentada com eficácia. H avia a esfera municipal, com o posto de saúde, a Secretaria M unicipal de Saúdeeo SAAE; havia a esfera estadual, com a equipe da Regional de Saúde e da sede da Secretaria Estadual de Saúde; e havia a esfera federal, com o CENEPI e a FUNASA. Por determinação isolada de cada uma das partes, foram incluídos também a 17a RS, a U niversidadeEstadual de Londrina (UEL), a UFRGS, a UniversidadeFederal deSão Paulo (UNIFESP) epesquisadores da Universidade Estadual do Norte Fluminense Darcy Ribeiro.

Segundo os depoimentos, o posto de saúde, que deveria centralizar os exames laboratoriaise o trabalho de informação à população, foi colocado à margem, prejudicando o processo de atendimento à sociedade. Entre os entrevistados diretamenteresponsáveis pelo enfrentamento do problema, houve um consensual entendimento de que as razões principais para essa falta de coordenação foi ausência de uma liderança forte e a inexperiência em ações desse tipo:

“Teve um 'fator externo' que atrapalhou bastante. A equipe organizada não chegou a funcionar a todo vapor. Faltou liderança (E1, ex-secre- tário municipal de saúde; entrevista concedida em agosto de 2003)

"Acho que [as pessoas de fora] ajudaram sim. M inha impressão é que eles ajudaram, mas também fez uma 'panela'. 0 quefaltou do nosso pessoal, é que ninguém tinha experiência e começamos a atender todo mundo. Começamos pensando 'pequeno'. Não pensamos enquanto epidemia, pensamos enquanto doença. Não tínhamos a vivência de separar o material e foi virando aquela bagunça, não teve um direcionamento, ninguém falou como tinha que ser feito". (E2, médica do posto de saúde; entrevista concedida em agosto de 2003)

"Eles estavam perdidos. A secretária [municipal deSaúde] estava mantendo muito contato com o estado de São Paulo, com o pessoal do M ini stério e esqueceu da equipe, de envolver a equipeno processo. A área da assistência ficou sem organização". (E3, funcionária da 14a RS; entrevista concedida em janeiro de 2005)

O comportamento de algumas autoridades foi outro motivo para os desentendimentos. Dois órgãos municipais estiveram diretamente envolvidos no problema: a Secretaria da Saúde e o SAAE. Nem a secretária de Saúde, nem o prefeito deSanta I sabel da época concederam entrevista à equipe da pesquisa, mas entre os que foram entrevistados foi unânime a percepção de que 0 prefeito omitiu-se de suas responsabilidades, 0 que acabou gerando certa confusão e desentendimento entre o pessoal do posto de saúde e a Secretaria de Saúde: “N a época da epidemia, a administração munici pal sumiu eficamos nós, SAAE eSM S, na linha de frente". (E4, diretor do SAAE, entrevista concedida em janeiro de 2005)

“O prefeito não assumiu a posição dele como prefeito. Elecontinuou fugindo atéo final do mandato. Ele largou, ele só fugia, dizia que aquilo não tinha nada a ver com a água. M esmo o SAAE ele largou na mão, a Saúde". (E5, médico, entrevista concedida em janeiro de 2005)

"O município, o prefeito, sempre se recusou a aceitar que existia o problema. Então quem enfrentou isso foram a Secretária deSaúde eo diretor do SAAE. Foram os que levaram as bordoadas". (E6, vereador egestor municipal, entrevista concedida em janeiro de 2005)

No dia 15, o jornal Folha de Londrina noticiou um movimento de protesto com centenas de pessoas, que reclamavam do atendimento no posto de saúde eque o reservatório de água continuava a ser utilizado. 0 movimento era liderado por várias professoras ${ }^{22}$.

Nesse mesmo dia, um novo titular foi nomeado para a Secretaria da Saúde do Paraná. No 
discurso de posse, ele afirmou que o combate ao surto de toxoplasmose seria sua prioridade de governo, envolvendo duas questões principais: primeiro, garantir um sistema eficaz de informação à população; segundo, traçar um diagnóstico preciso da doença.

$N$ os meses seguintes, o diagnóstico realmente foi feito e todo o problema de Santa Isabel demonstrou-se útil para aprimorar o conhecimento científico sobre a doença e sobre seus veículos de transmissão. M as, no que diz respeito à população, é possível afirmar que ela não foi satisfatoriamente atendida.

Em nova reportagem, a Folha de Londrina ${ }^{23}$ publicou os resultados oficiais dos exames realizados pelo H ospital Veterinário daU EL, queconfirmavam a contaminação do gato. Os veterinários da UEL iniciavam agora um processo de coleta de sangue nos gatos, cães e animais de produção de Santa Isabel do I vaí, com o propósito de fazer um "mapa da contaminação".

No final de janeiro, 0 jornal ${ }^{24}$ noticiava que os moradores de Santa I sabel pretendiam constituir uma Associação dos Infectados da Toxoplasmose e exigir do Estado uma reparação pelos danos sofridos. $\mathrm{Na}$ reportagem, um advogado afirmava que a associação pretendia entrar com uma ação civil pública de reparação de danos, além de processos criminais contra os responsáveis. 0 advogado estranhava o silêncio do M inistério Público na questão. Defato, o M inistério Público demorou a se pronunciar, e a associação também não se organizou nem naquele momento, nem nos meses seguintes.

Em 2002, em três oportunidades, os oftalmologistas da UFRGS e da UNIFESP retornaram à Santa Isabel para realizar novos exames na população. Em junho, a equipeconstatou que o número de vítimas já atingia cerca de 450 pessoas e que $15 \%$ dos casos apresentavam lesões oculares. Seis eram recém-nascidos. Em setembro, foi confirmado o registro de cerca de setecentas pessoas infectadas e 75 pacientes com lesões nos olhos ${ }^{25}$.

$\mathrm{N}$ a realidade, nunca ficou esclarecido exatamente quantas pessoas foram vitimadas, primeiro porque os números oferecidos pelas secretarias municipal e estadual não conferem e, segundo, porque um percentual dessa população procurou a rede hospitalar privada, não entrando nos índices da rede pública.

N esse ano, a Folha de Londrina publicou um artigo descrevendo o sentimento de revolta das pessoas atingidas pela doença. 0 reservatório causador do problema continuava a ser utiliza- do e a população sentia-se mal informada e discriminada, porque a cidade passou a ser vista com preconceito ${ }^{26}$. Na mesma reportagem, 0 jornal informava que o Ministério Público havia aberto um inquérito para investigar as responsabilidades criminais no episódio, mas a promotora explicava que o inquérito seria rapidamente concluído e, ao final, ela poderia pedir o arquivamento ou a denúncia criminal.

Três anos depois do surto, em janeiro de 2005, os autores desta pesquisa retornaram à Santa I sabel do Ivaí com a finalidade de concluir os trabalhos. Buscou-se verificar, a partir dos de poimentos de alguns dos atores-chave do processo, se nesse período teria havido mudanças no município e se os problemas com a água haviam sido resolvidos. Os fatos observados merecem ser expostos.

Em relação à situação política, o ex-prefeito saiu totalmente de cena. Provavelmente, a forma com que lidou com a epidemia de toxoplasmose foi um fator de desgaste que o levou ao completo isolamento político, perdendo apoio inclusive de seus secretários e ex-aliados. $\mathrm{N}$ em chegou a tentar a reeleição.

0 prefeito eleito em 2004 teve uma atuação importante durante a crise, agindo não apenas como médico, mas também como crítico da política exercida pelo ex-prefeito. $N$ a eleição, ele recebeu o apoio de uma ampla coligação (PP/PDT/ PT/PTB/PMDB/PL) e foi eleito com $68 \%$ dos votos válidos ${ }^{6}$.

$\mathrm{N}$ a nova administração municipal, estão vários políticos que tiveram papel de destaque no período da crise, como o vereador oposicionista que passou a ocupar a Secretaria de Administração e Finanças e 0 antigo diretor do SAAE, que retornou ao antigo posto.

Durante o surto de toxoplasmose, o vereador oposicionista foi uma das pessoas que procurou mobilizar a população e organizar protestos. O ex-diretor do SAAE sofreu forte crítica durante os momentos de maior crise, em virtude dos problemas da administração do sistema de água, pela qual era responsável. $M$ as retornou ao mesmo cargo por ser considerado um técnico. Com exceção dele, o grupo atualmente no governo municipal é o mesmo que criticava a ação da prefeitura anterior.

Indagados sobre qual a importância do de bate sobre a epidemia de toxoplasmose durante a campanha eleitoral, os entrevistados foram unânimes em afirmar que este não foi um tema da campanha. Contudo, passados mais de três anos e independentemente do fato do tema vir a 
público ou não, é certo que em 2005 a cidade ainda vivia sob o signo da epidemia, pois a atual administração continuava às voltas com o problema da organização do sistema de água, que permanecia não resolvido. A pesar da construção do novo reservatório, o sistema de distribuição de água era inadequado e estava inoperante.

Outro fato que merece registro é que a promotora pública do período da crise foi transferida de comarca e seu substituto entrou com uma ação contra o município em outubro de 2003, com o argumento de que as condições do reservatório permaneciam precárias. Além da ação, 0 M inistério Público entrou com uma liminar exigindo a urgente reparação no sistema de água, tendo em vista o perigo de uma nova contaminação. Sem dúvida, essa medida passou a preocupar a nova administração municipal, pois a cada dia de atraso na entrega da obra seria cobrada uma multa de $R \$ 1.000,00$, o que representaria um importante prejuízo para as contas do município. Na entrevista, o Secretário das Finanças demonstrou grande preocupação com as ações do promotor público.

Porém, o juiz indeferiu o pedido de liminar. Ao não aceitar a liminar, o juiz não acatou a idéia de que a situação do reservatório era de perigo iminente. Desse modo, não foi cobrada a multa diária de $R \$ 1.000,00$, passando o processo judicial a correr normalmente. Sabendo-se de quanto é morosa a Justiça brasileira, isso serviu para tranquilizar os novos administradores municipais.

A análise retrospectiva da epidemia mostra que o problema ocorreu em razão da precária conservação do reservatório de água. N ão se tratou de um descuido momentâneo, nem mesmo de um acidente fruto do acaso. Havia documentos de há muito mostrando que era preciso fazer reparos, consertos no reservatório para tornáIo mais seguro. Segundo o diretor do SAAE, há vinte anos a situação do reservatório de água já passava por um processo de deterioração, exigindo reformas: "Tem mais de vinte anos que está dessejeito. Em 1986, a 14a Regional deSaúde veio, pegou a equipe do SAAE e foram no reservatório. Tentaram esvaziar o reservatório, não conseguiram. Os funcionários daquela época ainda trabaIham aqui. As infiltrações eram maiores do que a bombinha puxava, não conseguiram. Foram embora. N ão interditaram o sistema, não multaram, não fizeram nada. Não tem um documento dizendo isso. Eu tenho relatórios da FU NASA de 1994... A Fundação veio no gabinete para tentar fazer aquele convênio de cooperação técnica, fotografou todo o sistema. Tenho as fotos, em 1994 estava tão ruim como estava em 2001. Pelo menos há vinte anos está do mesmo jeitinho. Caindo. Toda torta". (E4, entrevista concedida em janeiro de 2005)

Os argumentos de autodefesa do responsável pelo serviço de água foram confirmados por um ex-dirigente da 14a Regional de Saúde, que havia acompanhado todo esse processo na qualidadedefuncionário do Estado: “Em 1984, quando nós começamos o projeto de potabilidade de água, o monitoramento da água pelo estado, começamos num processo de assessoria aos SAAE. Eram serviços excluídos do processo PRONASA. Ao longo do tempo, [Santa I sabel] não fez investimento. A água dos poçoséágua de boa qualidade, mas o reservatório tinha uma série de infiltrações. Naquela época, colocava-seque tinha que ser feito investimento em saneamento básico pesado, trocar a rede, que tinha ainda boa parte em ferro galvanizado, estava toda enferrujada. Com trinta anos de uso, as próprias adutoras já tinham problema, era um sistema envelhecido. Só que o tempo foi passando enão foi feito investimento. A qualidadeestava sendo garantida, do ponto de vista da potabilidadenão estava tendo problema nenhum". (E7, entrevista concedida em janeiro de 2005)

Além desses depoimentos, há também as atas da Câmara Municipal que denunciam a situação, cobrando providências do prefeito. Três meses antes de o surto acontecer (em 22/08/01), um vereador apresentou na Câmara um relatório da vistoria que havia realizado no setor dos "reservatórios e casas de bombas de recalque" por determinação da própria Câmara. De acordo com o relatório, a casa de bomba: "A) necessita urgentemente de demolição da parte velha, em alvenaria e madeira, que encontra-se (sic) bastante danificada e sem condição de uso; B) se faz necessário a construção em alvenaria de uma nova casa [...]".

Quanto aos reservatórios, “A) necessitam de reparosurgentes para evitar a penetração deáguas acumuladas e de chuva para dentro dos mesmos; B) limpeza em volta dos reservatórios, com construção de canaletas para o desvio das águas das minas, que correm ao redor e sobre os mes-

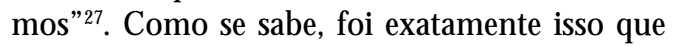
ocorreu três meses depois. A água da chuva le vou para dentro do reservatório oocistos de fe zes dos gatos que habitavam o local.

Observa-se, portanto, que há muito os reservatórios apresentavam problemas e que tanto as autoridades municipais quanto as estaduais incumbidas de controlar a qualidade da água tinham pleno conhecimento da situação. Foi um desleixo de décadas. 
Entre a população, contudo, não existia o mesmo grau de informação. Ao contrário, pelo fato de a água ser oferecida por um serviço autárquico por meio de poços artesianos, a impressão que preval ecia entrea sociedade era extremamente positiva. A de que a água era de uma qualidade superior à que vinha sendo oferecida nos outros municípios do Paraná: "Olha, a gente não tinha essa preocupação, a nossa água era considerada a melhor água do Paraná. Parabenizavam a nossa água: 'a água de vocês é mineral, a água de vocês é uma maravilha, não existe água igual!'”. (E8, em entrevista concedida aos autores em agosto de 2003)

Esse desconhecimento do quesucedia em uma cidade tão pequena demonstra o quanto o poder éinvisível ${ }^{28}$. 0 quanto questões políticas essenciais se processam às escondidas, sem que os cidadãos tenham conhecimento do que se passa. Entretanto, deve-se acrescentar que algumas variáveis políticas, presentes no município, contribuíram para piorar o relacionamento entre Estado esociedade.

Em primeiro lugar, observa-se uma instabilidade partidária que impede 0 desenvolvimento de mecanismos de controle social (mecanismos de accountability). Durante as entrevistas, esse dado ficou claro, sobretudo nas descrições sobre as composições e os acordos eleitorais que se sucedem eleição após eleição. Não se verifica na cidade a constituição das lealdades partidárias próprias dos sistemas políticos sedimentados. É certo que as dificuldades partidárias no Brasil são apontadas pelos estudiosos preocupados em determinar o comportamento dos políticos que trocam de siglas e deeleitores que migram deum partido a outro nas sucessivas eleições. Segundo vários autores, a média de transferências parti- dárias e de volatilidade eleitoral é significativamente alta no Brasi $\left.\right|^{29,30}$ e pesquisas recentes sobre o Paraná tendem a confirmar esses dados, sobretudo nos pequenos municípios politicamentetradicionais ${ }^{31}$.

Contudo, é preciso destacar que o comportamento político-partidário em Santa Isabel do I vaí insere-se ao grupo das situações de maior instabilidade partidária. Como é observável no Quadro 1, a volatilidade das siglas partidárias no município é espantosa.

Em 1996, o PMDB foi vitorioso ao eleger o prefeito e três vereadores. Quatro anos depois, nas eleições seguintes, o PM DB sequer participou das el eições majoritárias no município enão conseguiu el eger nenhum vereador. Em 2000, foi o PSD B que venceu, elegendo o prefeito equatro vereadores. Foi exatamente o período da epidemia de toxoplasmose. Em 2004, deu-se outra reviravolta política na cidade. O PSDB desapareceu do cenário municipal, não conseguindo eleger nem mesmo um vereador.

Em Santa I sabel, prevalece uma grande instabilidade política. Não se trata do controle de um grupo político fechado, quemonopoliza o poder no município; pelo contrário, nota-se uma competição político-eleitoral. 0 quehá éuma atomização partidária: segundo o Quadro 1, na Câmara de Vereadores, as nove cadei ras vêm sendo ocupadas por nada menos do que cinco partidos em cada gestão, sendo que as siglas não se mantêm de uma eleição a outra.

Em segundo lugar, um fator prévio, predeterminante, contribui para tornar o poder não transparente, que é o baixo grau de participação política da sociedade. Conforme foi visto, a população não conseguiu organizar a associação das vítimas da toxoplasmose. Segundo a Folha

Quadro 1. Resultados eleitorais: prefeito e vereadores em Santa Isabel do Ivaí por partidos e porcentagem de votos.

\begin{tabular}{|l|l|l|c|c|}
\hline \multirow{2}{*}{$\begin{array}{l}\text { Ano da } \\
\text { eleição }\end{array}$} & \multicolumn{2}{|c|}{ Pleito } & \multicolumn{1}{|c|}{ 20 colocado } & \multicolumn{1}{|c|}{ Vereadores } \\
\cline { 2 - 5 } 1996 & PMDB - 66\% & PDT - 32\% & PT - 2\% & $\begin{array}{l}\text { PM DB: 3; PPB:2; } \\
\text { PSD B:2; PDT: 1; PTB:1 }\end{array}$ \\
\hline 2000 & PSDB - 58\% & $\begin{array}{l}\text { PPS/PFL/PL/PPB/PP - } \\
40 \%\end{array}$ & PTB - 2\% & $\begin{array}{l}\text { PSDB: 4; PPS: 2; PT: 1; } \\
\text { PDT: 1; PL: } 1\end{array}$ \\
\hline 2004 & $\begin{array}{l}\text { PP/PDT/PT/PTB/ } \\
\text { PMDB/PL - 68\% }\end{array}$ & PFL - 32\% & ************** & $\begin{array}{l}\text { PFL: 3; PP: 2; PL: 2; PT: } \\
\text { 1; PTB: } 1\end{array}$ \\
\hline
\end{tabular}

Fonte: Tribunal Superior Eleitoral6. 
de Londrina, nos momentos mais críticos, chegou a ser formado um movimento de protesto, mas que se limitou ao controle de umas poucas lideranças políticas. A fala de uma delas deixa claro como se dá essa relação de representação: "Eu sou uma pessoa que oriento as pessoas. Assim: 'é uma pessoa muito humana. Falam que ela ébocuda, queela éruim, masénada, éa melhor pessoa que orienta'. Se eu falar pra vocêse joga ali que ali tem ouro, eles vão. Então, é porque confiam na gente. Eu fiquei conversando com as vítimas e falei: 'o que precisar a gente esta aí. 0 mal de vocês é ter demorado muito e não ter procurado a gente na hora certa'. M as, enfim, procuraram e o que eu pude fazer era isso, esclarecer a verdade". (E8, entrevista concedida aos autores em janeiro de2005)

Trata-se de um relacionamento desigual, paternalista, no qual a população procura por alguém quelhedêum pouco de amparo. Em pleno século XXI, Santa Isabel do I vaí faz lembrar as descrições deV ictor Nunes Leal ${ }^{2}$ sobre os pequenos municípios do interior do Brasil. Politicamente, ainda prevalece uma relação de dependência, sem consciência dos direitos, sem ações deliberadas de reivindicação. N esse quadro em que não aparecem cidadãos a quem prestar contas, os representantes políticos mantêm os mecanismos personalistas da política tradicional, mesmo com a regulamentação dos procedimentos democráticos instaurados pela Constituição de 1988.

\section{Considerações finais}

A pesquisa sobre a epidemia de toxoplasmose em Santa I sabel do I vaí permite al gumas conclusões. Em primeiro lugar, ficou demonstrado que o município não dispunha de profissionais preparados para enfrentar situações críticas e inesperadas de saúde, o que deve ser uma realidade na maioria dos pequenos municípios. M esmo as instâncias regionais da secretaria estadual estão desfalcadas de quadros técnicos, embora seja preciso notar que partiu da 14a RS o planejamento das ações coletivas de saúde, que levaram ao controle da doença.

Faltou liderança local competente nos dias mais importantes da crise, aumentan do o desencontro de informações e dificultando o trabal ho em equipe. Houveum conflito deautoridadeentre os agentes municipais, estaduais e federais de Saúde, prevalecendo a improvisação em lugar de uma bem estruturada organização das ações. M esmo a competência clínica demonstrada pe los médicos locais não foi acompanhada pela capacidade de raciocinar em termos de saúde coletiva, levando-os à tentativa frustrada de enfrentar o problema com o arsenal terapêutico do tratamento clínico individual.

Essas condiç̧ões levaram a uma situação apavorante para a população de Santa I sabel do I vaí no período compreendido entre as vésperas do $N$ atal de2001 emeados dejaneiro de 2002. Quando a doença se espalhou de uma forma aparentemente sem controle, a dificuldade das autoridades sanitárias em transmitir confiança à população criou um generalizado estado de pânico.

Em segundo lugar, vale destacar que os avanços científicos decorrentes da epidemia não contemplam uma reflexão fundamentada nos referenciais da atenção primária ambiental e nos movimentos das cidades saudáveis. A curva epidêmica de toxoplasmose de Santa I sabel do I vaí, que abrange o período de novembro de 2001 a janeiro de $2002^{32}$, não espelha a realidade do ponto de vista médico-sanitário e sociopolítico do problema. Caso a curva incorporasse também as dimensõesnão biológicas da epidemia, seela consistisse uma "curva interdisciplinar da epidemia", os anos anteriores de descaso dos gestores municipais e das autoridades médico-sanitárias teriam que ser considerados.

Da mesma forma, seriam levadas em conta as sequelas da comunidade atingida, que vão muito além da data de identificação do último caso clínico da doença. Avaliações acerca dos seus danos $^{33}$ apontam que, durante muitos anos, as autoridades, as vítimas e os profissionais de saúde do município ainda se verão envolvidos em demandas médicas e processos jurídicos ${ }^{34}$. A qualidade da água fornecida para consumo humano no município era precária e se mantinha assim até o momento de conclusão da pesquisa (2005).

Em terceiro lugar, concordando com o que escreveu Scliar, "É possível balizar a historia por eventos econômicos, ou pela luta de classes. M as também por meio de doenças queacarretam grandes grupos populacionais, as epidemias" 35 , não resta dúvida que, guardadas as devidas proporções, a história do município de Santa Isabel do I vaí está marcada pela epidemia detoxoplasmose.

Como sustenta o Relatório de Desenvolvimento Humano 2006, a maior barreira para re solver o problema de acesso à água e saneamento em países em desenvolvimento é a falta de vontade política aliada à má gestão ${ }^{36}$. A pesquisa procurou mostrar a dificuldade dos gestores públicos em tomar atitudes coordenadas em direção à solução do problema. No momento ex ante ao surto, disputas de caráter político-eleito- 
ral e denúncias oriundas do Legislativo municipal e do Conselho Municipal de Saúde não tiveram o efeito de interferir no processo decisório para mover o município em direção às reformas necessárias. No decorrer da crise, nem mesmo 0 M inistério Público teve uma atuação relevante em favor da população. E no período ex post, em que a cidade teve oportunidade política de responder à má administração anterior, nota-se a morosidade da nova administração no encaminhamento dos problemas. 0 que se constata é que os mecanismos democráticos não foram suficientes para estabelecer canais efetivos entrea sociedade e os diversos agentes estatais. A sociedade permaneceu desinformada e mal assistida.

Para concluir, conforme apontam Freitas e Freitas ${ }^{37}$, em relação às açõesintersetoriaise a uma gestão participativa, há muito que se avançar na vigilância da qualidade da água de consumo humano, que deve incorporar de fato os diferentes atores sociais na negociação dos conflitos enos processos decisórios relativos ao tema. Enfim, o Brasil tem um caminho longo a percorrer no que diz respeito à qualidade de vida de sua população.

\section{Colaboradores}

MJ Almeida, LHH Oliveira, RL Freire e IT Navarro participaram da concepção, coleta de dados, análise e redação final, sendo que o primeiro, além disso, desenvolveu as funções de coordenador do projeto de pesquisa.
Agradecimentos

Agradecemos a compreensão e apoio manifestados pelos dirigentes e profissionais da equipe da Secretaria M unicipal de Saúde de Santa I sabel do Ivaí e aos profissionais Lúcio Santos e Eunice Gomes, da 14a Regional de Saúde. Um agradecimento especial à jornalista $\mathrm{M}$ arta $\mathrm{M}$ edeiros Fanha, que atuou no episódio como repórter da sucursal de Maringá da Folha de Londrina. Seu compromisso com a ética profissional e em de fesa de uma sociedade mais justa foi decisivo para trazer à tona e manter em evidência, durante semanas, uma problemática médico-sanitária esociopolítica que teria, não fosse ela, permanecido nos subterrâneos da história da saúde pública paranaense. 


\section{Referências}

1. Programa das Nações Unidas para o Desenvolvimento. Atlas do desenvolvimento humano no brasil. Perfil municipal - Santa Isabel do Ivaí (PR). 2000. [site da Internet] [acessado 2007 nov 29]. Disponível em: http://www.pnud.org.br/atlas/instalacao/ index.php

2. Leal VN. Coronelismo, enxada e voto. 5a ed. São Paulo: Alfa-O mega; 1986.

3. Instituto Brasileiro de Geografia e Estatística (IBGE). Cidades. 2000. [site da Internet] [acessado 2007 nov 29]. Disponível em: http://wwwl.ibge.gov.br/cidadesat/topwindow.htm?1

4. Instituto Brasileiro de Geografia e Estatística. Perfil dos municípios brasileiros, finanças públicas (19982000). Paraná - Santa Isabel do Ivaí. 1999. [site da Internet] [acessado 2007 nov 29]. Disponível em: http://www.ibge.gov.br/financasmunic/index.htm

5. Dahl R. Poliarquia. São Paulo: Edusp; 1997.

6. Brasil. Tribunal Superior Eleitoral. Eleições - Resultados. [site da Internet]. Disponível em: http:// www.tse.gov.br

7. Vianna LW, organizador. A democracia e os três poderes no Brasil. Rio de Janeiro: IUPERJ; 2002.

8. Sadek MT, Cavalcanti RB. The New Brazilian Public Prosecution: an agent of accountability. In: M ainwaring S, Welna C, editors. Democratic accountability in Latin America. Oxford: Oxford University Press; 2002. p. 201-227.

9. Wright MGM. Atención primaria ambiental para el siglo XXI. Rev. Panam. Salud Públ. / Pan Am. J. Public Health 1998; 4(4):290-296.

10. Organização Pan-Americana da Saúde. Divisão de Saúde e Ambiente. Programa de Qualidade Ambiental. Atenção primária ambiental (APA). Washington, D.C.: OPAS; 1999.

11. Westphal MF. O movimento cidades/municípios saudáveis: um compromisso com a qualidade de vida. Cien Saude Colet 2000; 5(1):39-51

12. Giovanni Sartori. A Política: lógica e método nas ciências sociais. 2ª ed. Brasília: UnB, 1997.

13. Frenkel JK. Toxoplasmosis in human beings. J Am Vet M ed Assoc 1990;196(2):240-248.

14. Tenter AM, Heckeroth AR, Weiss LM. Toxoplasma gondii: from animals to humans. Int J Parasitol 2000; 30:1217-1258.

15. Bowie WR, King AS, Werker DH, Isaac-Renton JL, Bell A, Eng SB, Marion SA. Outbreak of toxoplasmosis associated with municipal drinking water. Lancet 1997; 350(9072):173-177.

16. Silveira CAM. Toxoplasmose - dúvidas e controvérsias. 1a ed. Erechim: Edipafes; 2002.

17. Dubey JP, Navarro IT, Sreekumar C. Toxoplasma gondii infections in cats from Paraná, Brazil: seroprevalence, tissue distribution, and biologic and genetic characterization of isolates. J Parasitol 2004; 90(4):721-726.

18. Brasil. M inistério da Saúde. Fundação Nacional de Saúde. Surto de Toxoplasmose no Município de santa Isabel do Ivaí - Paraná. Bol Eletro Epidemiol 2002; 2(3):2-9.

19. Medeiros M. Cidade em alerta contra a toxoplasmose. Folha de Londrina 2001; 26 dez. p. 7.
20. Medeiros M. Aumentam as notificações de casos de toxoplasmose. Folha de Londrina 2001; $28 \mathrm{dez}$. p. 7.

21. Medeiros M. Toxoplasmose: $8 \%$ têm lesão ocular. Folha de Londrina 2002; 14 jan. p. 7.

22. Medeiros M. Cidade pede socorro a ministro. FoIha de Londrina 2002; 15 jan. p. 6. w

23. Parra L. Exames ligam gata à toxoplasmose. Folha de Londrina 2002; 19 jan. Cidade:4.

24. M edeiros M. Surto gera ação contra governo. FoIha de Londrina 2002; 29 jan. p. C4.

25. Parra L. M édico conclui pesquisa sobre toxoplasmose. Folha de Londrina 2002; 17 set.

26. Medeiros M. MP investiga surto de toxoplasmose. Folha de Londrina 2002; 23 jun. Paraná:13.

27. Tavares M. Câmara Municipal de Santa Isabel de Ivaí. Comissão de Obras e Serviços Públicos. Relatório. Santa Isabel de Ivaí: Câmara M unicipal; 2001.

28. Bobbio N. O futuro da democracia: uma defesa das regras do jogo. Rio de Janeiro: Paz e Terra; 1997.

29. Kinzo MD'A. Os partidos no eleitorado: percepções públicas e laços partidários no Brasil. RBCS [periódico na Internet]. 2005 [acessado ano mês dia]; 20(57):[ cerca de 18 p.]. Disponível em: http:/ /www.scielo.br/pdf/rbcsoc/v20n57/a05v2057.pdf

30. M elo CR. Retirando as cadeiras do lugar: migração partidária na Câmara dos Deputados (1985-1998) [tese]. Belo Horizonte (M G): UFM G; 1999.

31. Codato NA, Santos FJ, organizadores. Partidos e eleições no Paraná: uma abordagem histórica. Edição Comemorativa - 60 Anos do Tribunal Regional Eleitoral do Paraná. Curitiba: TRE-PR; 2006.

32. de Moura L, Bahia-Oliveira LM, Wada MY, Jones JL, Tuboi SH, Carmo EH, Ramalho WM, Camargo NJ, Trevisan R, Graça RM, da Silva AJ, Moura I, Dubey JP, Garrett DO. Waterborne Toxoplasmosis, Brazil, from field to gene. Emerg Infect Dis 2006; 12(2):326-329.

33. Medeiros M. Exames avaliam danos da toxoplasmose. Folha de Londrina 2002; 16 jun. p. 11.

34. Guerim M. Sequelas: As vítimas da toxoplasmose. Folha de Londrina 2007; 16 out. Cidades:3.

35. Scliar M. Prefácio. In: Ujvari SC, organizador. A história e suas epidemias. Rio de Janeiro: SENAC; 2003. p. 9-1.1

36. Acesso a água esbarra em vontade política. Folha de São Paulo 2006; 10 nov. Brasil:A13.

37. Freitas $M B$, Freitas $C M$. A vigilância da qualidade da água para consumo humano - desafios e perspectivas para o Sistema Único de Saúde. Cien Saude Colet 2005; 10(4):993-904.

Artigo apresentado em 25/03/2008

A provado em 31/10/2008

Versão final apresentada em 05/12/2008 